\title{
Perioperative outcomes of robotic-assisted laparoscopic radical prostatectomy, laparoscopic radical prostatectomy and open radical prostatectomy: 10 years of cases at Ramathibodi Hospital
}

\author{
Kun Sirisopana ${ }^{1}$, Pocharapong Jenjitranant ${ }^{1}$, Premsant Sangkum ${ }^{1}$, Kittinut Kijvikai ${ }^{1}$, Suthep Pacharatakul ${ }^{2}$, \\ Charoen Leenanupun ${ }^{1}$, Wachira Kochakarn ${ }^{1}$, Wisoot Kongchareonsombat ${ }^{1}$ \\ ${ }^{1}$ Division of Urology, Department of Surgery, Faculty of Medicine, Ramathibodi Hospital, Mahidol University, Bangkok, Thailand; ${ }^{2}$ Division of \\ Urology, Department of Surgery, Police Hospital, Bangkok, Thailand \\ Contributions: (I) Conception and design: W Kongchareonsombat, C Leenanupun; (II) Administrative support: P Sangkum, K Kijvikai; (III) Provision \\ of study materials or patients: All authors; (IV) Collection and assembly of data: K Sirisopana, P Jenjitranant; (V) Data analysis and interpretation: K \\ Sirisopana, W Kochakarn; (VI) Manuscript writing: All authors; (VII) Final approval of manuscript: All authors. \\ Correspondence to: Wisoot Kongchareonsombat. Division of Urology, Department of Surgery, Faculty of Medicine, Ramathibodi Hospital, Mahidol \\ University, Bangkok, Thailand. Email: wisoot2002@hotmail.com.
}

Background: This study aims to compare the perioperative and pathological outcomes of open radical prostatectomy (ORP), laparoscopic radical prostatectomy (LRP), and robotic-assisted laparoscopic radical prostatectomy (RALRP) at Ramathibodi Hospital within Mahidol University in Thailand.

Methods: From January 2008 to July 2017, 679 RPs were performed. Patients' data were collected retrospectively to evaluate their perioperative and pathological outcomes. This data included the age, body mass index (BMI), serum prostate specific antigen (PSA) level, clinical stage, Gleason score (GS) from biopsy, operative time, estimated blood loss (EBL), perioperative complications, blood transfusion rate, adjacent organ injury rate, length of hospital stay, pathological stage, GS of the biopsy specimen, specimen weight (g), and marginal status of the patients.

Results: Of the 679 RPs performed, 128 (19.28\%) were ORPs, 241 (36.30\%) were LRPs, and 295 (44.43\%) were RALRPs. Patients who underwent a RALRP had a significant advantage in EBL $(1,600,500$, and $300 \mathrm{~mL}$ for ORPs, LRPs, and RALRPs, respectively), overall complications, and blood transfusion rate. As they are minimally invasive techniques, LRP and RALRP presented an advantage in terms of the length of hospital stay (an average of 9, 6, and 6 days for ORPs, LRPs, and RALRPs, respectively) and adjacent organ injury rate. ORPs also had the shortest operative time (160, 210, and $200 \mathrm{~min}$ for ORPs, LRPs, and RALRPs, respectively). However, the specimen weight and marginal status were similar in all of the techniques.

Conclusions: Minimally invasive RP techniques, such as LRPs and RALRPs, appear to be safe, have significantly better perioperative outcomes than ORPs, and have comparable pathological outcomes to those of ORPs.

Keywords: Prostate cancer; radical prostatectomy; laparoscopy; robot-assisted laparoscopic surgery; open surgery; perioperative outcome

Submitted Mar 17, 2019. Accepted for publication Aug 14, 2019.

doi: $10.21037 /$ tau.2019.09.03

View this article at: http://dx.doi.org/10.21037/tau.2019.09.03 


\section{Introduction}

Prostate cancer is the fifth most common cancer in Thai men (1), and the number of cases continues to rise despite the presence of improved healthcare and active screening. Radical prostatectomy (RP) is a standard of care in the treatment of clinically localised prostate cancer and is an option for the treatment of locally advanced prostate cancer. $\mathrm{RP}$ can be performed using open radical prostatectomy (ORP), laparoscopic radical prostatectomy (LRP), or robotic-assisted laparoscopic radical prostatectomy (RALRP) techniques. In the past decade, especially in Asia, the minimally invasive RP techniques LRP and RALRP have been significantly favoured, as they provide better visualisation of the surgical process and anatomy $(2,3)$. In addition, instruments and techniques are being continuously improved, making the operation easier to perform and improving perioperative outcomes, such as the operative time, estimated blood loss (EBL), transfusion rate, adjacent organ injury rate (4-6), oncological outcomes $(4,7)$, and functional outcomes $(7,8)$.

Although there are abundant data from high-volume centres related to the outcomes of ORPs, LRPs, and RALRPs, according to our data, there are no studies that compare the outcomes of the three techniques specifically in Thailand. The objective of this study, therefore, was to evaluate and compare the perioperative and pathological outcomes of ORPs, LRPs, and RALRPs in a Thai context.

\section{Methods}

\section{Population and surgical techniques}

Between January 2008 and July 2017, 679 prostate cancer patients were treated using a RP at Ramathibodi Hospital in Thailand. Of these patients, 128 had undergone ORP, 241 had undergone LRP, and 295 patients had undergone RALRP. The remaining 15 patients were excluded from the study due to incomplete data. The principles of the Helsinki Declaration were followed during the study, and the confidentiality of the patients' data was guaranteed. The Committee for Research of the Faculty of Medicine, Ramathibodi Hospital, Mahidol University approved the study (date of approval: 01 October 2018, ID 07-61-70).

The ORPs were performed in a retropubic fashion using Vicryl No.1 to ligate dorsal venous complex, the LRPs were performed in an extraperitoneal fashion using $\mathrm{CO}_{2}$ to create a pneumoperitoneum at abdominal pressure of $15 \mathrm{mmHg}$, and the RALRPs were performed in an intraperitoneal fashion using the da Vinci Surgical System $\mathrm{Si}$. The operations were selected for each patient based on the collaborative decision of the patient and doctor.

The nerve-sparing RPs were performed in some cases, except in extensive cancer in the biopsy specimens, preoperative poor-quality erections, current and future lack of a sexual relationship, or other medical conditions that may adversely affect erections (e.g., diabetes mellitus, hypertension, psychiatric diseases, neurologic diseases, or medications that produce erectile dysfunction). However, we shared decision making with the patients and surgeon dependent.

Six instructor surgeons participated in this study. Two surgeons always performed ORPs while the other four surgeons performed all three techniques.

\section{Baseline characteristics and preoperative parameters}

The following data were collected from all patients: age, body weight $(\mathrm{kg})$, height $(\mathrm{cm})$, body mass index (BMI), prostate-specific antigen (PSA) level, underlying disease, clinical stage (TNM classification), and the Gleason score (GS) of the biopsy specimen.

\section{Perioperative outcomes}

Perioperative outcomes included: operative time (minutes); estimated blood loss (EBL) (mL); perioperative complications, including transfusion rate; adjacent organ injury of the bladder, rectum, ureter, bowel, or blood vessel; and length of hospital stay (days), which was defined by subtracting the date of admission from the date of discharge.

\section{Pathological outcomes}

All specimens were evaluated by an experienced uropathologist, in accordance with the National Comprehensive Cancer Network (NCCN) guidelines, who reported the prostatic weight (g), pathological stage, GS of the specimen, and the marginal status. A positive surgical margin (PSM) was defined as cancer cells extending to the inked surface of the specimen (9).

\section{Statistical analysis}

A descriptive study was performed. The data were analysed using an unpaired $t$-test, a Kruskal-Wallis test, and a Chi- 
square test to identify the statistical significance of the difference in means \pm standard deviation, median (IQR), and proportions, respectively. Analysis was performed using Stata version 14 , with a $\mathrm{P}$ value of $<0.005$ considered to be statistically significant.

\section{Results}

The demographic data and preoperative parameters are presented in Table 1. The ORPs, LRPs, and RALRPs were not statistically different in terms of median age $(68,68$, and 68 years, respectively; $\mathrm{P}=0.716$ ), median body weight (67.2, 66.4 , and $68.1 \mathrm{~kg}$, respectively; $\mathrm{P}=0.100$ ), median height $(165,165$, and $165 \mathrm{~cm}$, respectively; $\mathrm{P}=0.391)$, median BMI (24.3, 24.2, and $24.6 \mathrm{~kg} / \mathrm{m}^{2}$, respectively; $\mathrm{P}=0.218$ ), or median PSA (10.94, 10.60, and $11.82 \mathrm{ng} / \mathrm{mL}$, respectively; $\mathrm{P}=0.319)$. The clinical stage, however, presented significantly different data in each group $(\mathrm{P}=0.008)$. The GS of the biopsy specimens in the RALRPs was statistically significantly higher than that of the ORPs and LRPs $(7.04 \pm 1.01,6.89 \pm 1.31$, and $6.74 \pm 1.02$, respectively; $\mathrm{P}=0.001$ ); however, there was no difference between those of the ORP and LRP groups $(\mathrm{P}>0.005)$.

The perioperative outcomes (Table 2) show that the operative time was significantly lower in ORPs than in LRPs and RALRPs $(160,210$, and 200 minutes, respectively; $\mathrm{P}<0.001$ ), but there was no difference between the operative times of LRPs and RALRPs $(\mathrm{P}>0.05)$. Patients who underwent RALRPs had the lowest EBL by a significant margin $(1,600,500$, and $300 \mathrm{~mL}$ for ORPs, LRPs, and RALRPs, respectively; $\mathrm{P}<0.001$ for RALRPs vs. LRPs and $\mathrm{P}<0.001$ for LRPs vs. ORPs). The lowest overall complications were also observed in patients who underwent RALRPs in comparison to the other two groups $(81.25 \%, 29.05 \%$, and $8.81 \%$ for ORPs, LRPs, and RALRPs, respectively; $\mathrm{P}<0.001)$, and the same was noted for transfusion rates $(69.35 \%, 23.48 \%$, and $5.10 \%$ for ORPs, LRPs, and RALRPs, respectively; $\mathrm{P}<0.001$ for RALRPs $v$ s. LRPs and $\mathrm{P}<0.001$ for LRPs $v s$. ORPs). It was observed that the adjacent organ injury rate was highest in ORP cases (8.94\%, 3.46\%, and $0.68 \%$ for ORPs, LRPs, and RALRPs, respectively; $\mathrm{P}<0.001$ for ORP $v s$. LRPs and RALRPs and $\mathrm{P}>0.05$ for LRPs $v s$. RALRPs). When the length of hospital stay was analysed, although no statistical difference was found between the minimally invasive techniques (i.e., LRPs and RALRPs), it was significantly longer in the ORP technique (9, 6, and 6 days for ORPs, LRPs, and RALRPs, respectively; $\mathrm{P}<0.001$ for ORPs vs. LRPs and RALRPs and
$\mathrm{P}>0.05$ for LRPs $v s$. ORPs).

The pathological outcomes (Table 3) show that the pathological stage was significantly different in each group $(\mathrm{P}=0.001)$. The GS of the specimens was significantly higher in the RALRP group than it was in the other two groups $(7.10 \pm 1.03,7.12 \pm 1.00$, and $7.31 \pm 0.93$ for ORPs, LRPs, and RALRPs, respectively; $\mathrm{P}=0.018$ for RALRPs vs. LRPs and ORPs and $\mathrm{P}>0.05$ for ORPs vs. LRPs). The specimen weight was not significantly different among the three techniques $(39.3,38.4$, and $37.3 \mathrm{~g}$ for ORPs, LRPs, and RALRPs, respectively; $\mathrm{P}=0.669)$. PSM was also observed as not significantly different among the three groups $(33.04 \%, 40.63 \%$, and $39.15 \%$ for ORPs, LRPs, and RALRPs, respectively; $\mathrm{P}=0.383$ ).

\section{Discussion}

$\mathrm{RP}$ is the standard of care in the treatment of clinically localised prostate cancer and is a treatment option in locally advanced prostate cancer. At Ramathibodi Hospital in Thailand, ORP was preferred by two experienced urologists because of the introduction of nerve-sparing ORP, developed by Walsh and Donker (10), and several modifications to the technique; good outcomes have been achieved through it, both pathological (11-13) and functional $(11,13,14)$. However, after the standardisation of LRP techniques (15), the use of LRP has gradually grew, and it became the method of choice at Ramathibodi Hospital in 2007 (16).

In 2013, RALRP was then also adopted at the hospital, displacing the other two procedures due to its many advantages. RALRP provides a clear, three-dimensional (3D) view of the operative field and facilitates suturing and dissection by substituting large-scale hand movement with tiny instrument movement, which reduces vibration and frees the grasp to allow for shaft rotation movement at the tip (EndoWrist, Intuitive Surgical). This can be particularly useful for surgeons who do not have advanced laparoscopic skills. However, RALRP does have some limitations, such as the lack of haptic feedback, a high initial and procedural cost, and a steep learning curve $(17,18)$. Despite this, it has been observed that EBL is lowered when surgeons have better visualisation of the anatomy with a $3 \mathrm{D}$ view and magnification, the ability to more accurately and perform fine movements of instruments, and the ability to perform a tamponade effect within a vessel using $\mathrm{CO}_{2}$, all of which are possible using RALRP $(19,20)$. In our data, the median EBL was significantly lower in RALRPs than it was in LRPs 
Table 1 Demographic data and pre-operative parameters of ORP, LRP and RALRP

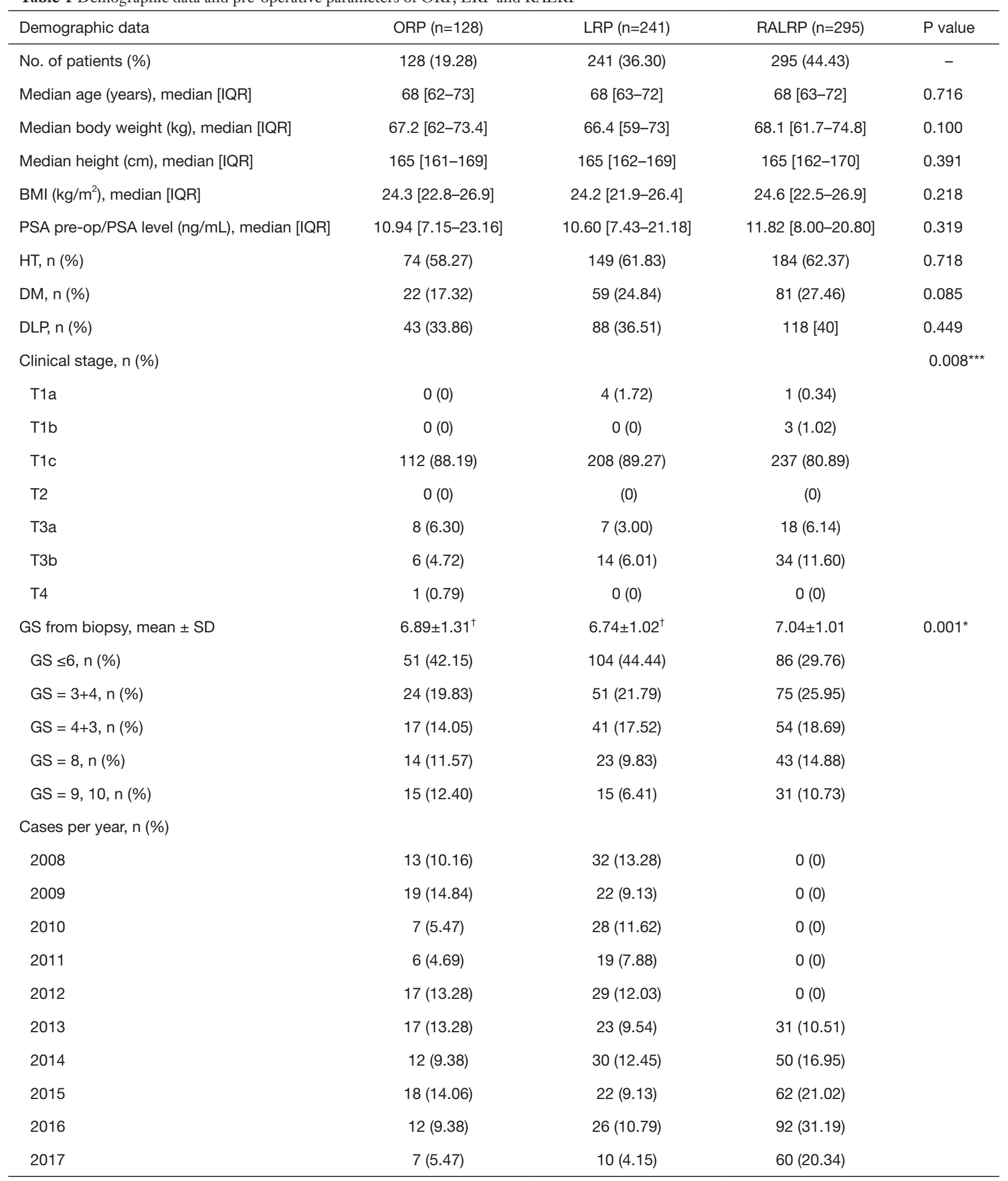

Table 1 (continued) 
Table 1 (continued)

\begin{tabular}{lccc}
\hline Demographic data & ORP $(\mathrm{n}=128)$ & $\operatorname{LRP}(\mathrm{n}=241)$ & $\mathrm{RALRP}(\mathrm{n}=295)$ \\
\hline Participant surgeons, $\mathrm{n}$ & & 2 & 0 \\
2008 & 4 & 2 & 0 \\
2009 & 4 & 2 & 0 \\
2010 & 4 & 2 & 0 \\
2011 & 4 & 2 & 0 \\
2012 & 4 & 2 & 2 \\
2013 & 4 & 2 & 2 \\
2014 & 4 & 2 & 2 \\
2015 & 4 & 4 & 4 \\
2016 & 6 & 4 & 4 \\
2017 & 6 & 2 & \\
\hline
\end{tabular}

${ }^{\dagger}, \mathrm{P}>0.05$. *, comparison of groups by unpaired $t$-test. ${ }^{* * *}$, comparison of groups by Chi-square test. BMI, body mass index; PSA, prostatespecific antigen; HT, hypertension; DM, diabetes mellitus; DLP, dyslipidaemia; GS, Gleason score.

or ORPs $(\mathrm{P}<0.001$ for RALRPs vs. LRPs and $\mathrm{P}<0.001$ for LRPs vs. ORPs) and a lower rate of transfusion was also found ( $\mathrm{P}<0.001$ for RALRPs vs. LRPs and $\mathrm{P}<0.001$ for LRPs vs. ORPs).

Additionally, in our study, the adjacent organ injury rate was found to be significantly lower in the LRP and RALRP groups than in the ORP group $(\mathrm{P}<0.001$ for ORPs $v s$. LRPs and RALRPs and $\mathrm{P}>0.05$ for LRPs vs. RALRPs). This can be explained by the better visualisation of the periprostatic anatomy and the ability to more precisely control the instrument in LRPs and RALRPs. The main organ affected by a RP is the rectum, which correlates to advanced tumours, lower surgeries volume, and prior radiation (21).

The advantages of minimally invasive techniques have led to a significant decrease in complications associated with these surgeries. When comparing the length of hospital stay, LRPs and RALRPs were shown to require significantly shorter stays than ORPs $(\mathrm{P}<0.001$ for ORPs $v s$. LRPs and RALRPs and $\mathrm{P}>0.05$ for LRPs $v s$. ORPs), confirming the findings of previous studies $(22,23)$. However, in a study by Wallerstedt et al. (23), the lengths of hospital stay in ORPs and RALRPs were 4.1 and 3.3 days, respectively, which is shorter than the present study. This can be contributed to an institute practice that routinely discharged patients after the closed-suction pelvic drain is removed. However, many factors such as socioeconomic status, inexpensive room rates, anxiety, and patient pain tolerance, any of which might affect the length of a hospital stay

Furthermore, the data show that the median operative time was significantly shorter for ORPs $(179,236$, and 187 minutes for ORPs, LRPs, and RALRPs, respectively) than it was for minimally invasive surgery (MIS), confirming the findings of previous studies (13). The median difference between the operating times of ORPs and MIS is significantly larger during the early phase of learning curve, but this gap shrinks as surgeons gain experience with the LRP and RALRP methods. This implies that RALRP provides a simpler method that ultimately allows for a shorter operative time compared to LRP.

The oncological control of RP in prostate cancer can be measured by PSM, the biochemical recurrence (BCR) rate, time to biochemical recurrence, local recurrence, and distant metastasis (4). Sachdeva et al. (24) and other researchers (25-28) have shown that a PSM in prostate cancer is considered an adverse oncologic outcome, associated with an increased likelihood of BCR. However, the significant predictors of BCR are tumour volume, a high GS, and a high pre-operative PSA. In our study series, there was no statistically significant difference in PSM among the three studied techniques, which is consistent with results of the other literature (11-13). Although the PSM rate in our study was high in comparison with large series data, ranging in a series from $12 \%$ (11) to $11 \%$ to $50 \%$ and, in recent meta-analysis, from $12.1 \%$ to $41.3 \%$ (12), 
Table 2 Perioperative outcomes ORP, LRP and RALRP

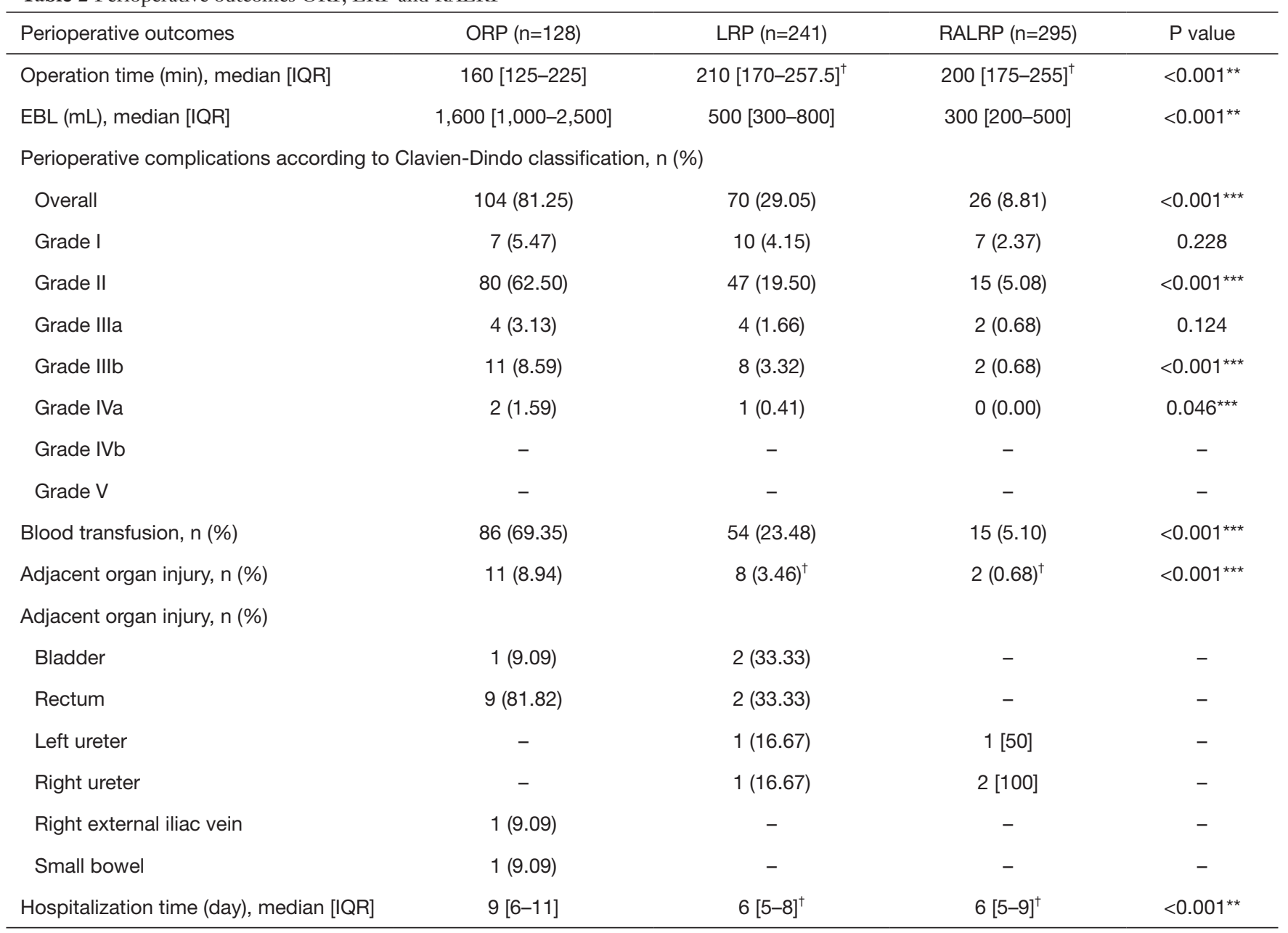

EBL, estimated blood loss. ${ }^{\dagger}, \mathrm{P}>0.05 .{ }^{* \star}$, comparison of groups by Kruskal-Wallis test. ${ }^{* \star \star}$, comparison of groups by Chi-square test.

this can be affected by the multiple surgeons who participated in this study, given the difference in learning curves. For example, in the present study, there were two new instructor surgeons who had just started performing RALRP in 2016. In addition, after the subgroup analysis, the majority of the PSM was in the T3 stage which can result from nature of the cancer that has been extended beyond the prostatic capsule (Tables $S 1, S 2$ ).

Moreover, patients with PSM are typically given two options: external beam radiation therapy (proton beam radiation) with or without androgen deprivation therapy (ADT) and observation. Unfortunately, data related to the rate of conversion and catheterisation time could not be collected to determine outcomes, as this study was retrospectively conducted. To determine the functional outcomes, such as incontinence and erectile dysfunction, the authors are assembling data and will report on these findings in a following study.

We would like to highlight that our study had some limitations. First, this was a retrospective study that compared different surgical techniques, and these different techniques were performed by different surgeons; as such, bias may exist in the process of evaluating the outcomes of the procedures. Second, this study lacked data about the oncological and functional follow-up. This would be improved by conducting a prospective randomised study with a higher case volume, which would prevent biases and provide much more accurate results.

\section{Conclusions}

As minimally invasive techniques, LRP and RALRP are 
Table 3 Pathological outcomes of ORP, LRP and RALRP

\begin{tabular}{|c|c|c|c|c|}
\hline Pathological outcomes & ORP $(n=128)$ & $\operatorname{LRP}(n=241)$ & $\operatorname{RALRP}(\mathrm{n}=295)$ & $P$ value \\
\hline $\mathrm{T} 2 \mathrm{a}$ & $10(7.87)$ & $35(14.58)$ & $18(6.16)$ & \\
\hline $\mathrm{T} 2 \mathrm{~b}$ & $10(7.87)$ & $9(3.75)$ & $3(1.03)$ & \\
\hline $\mathrm{T} 2 \mathrm{c}$ & $49(38.58)$ & $98(40.83)$ & $138(47.26)$ & \\
\hline Т3b & $34(26.77)$ & $44(18.33)$ & $64(21.92)$ & \\
\hline T4 & $0(0)$ & $1(0.42)$ & $0(0)$ & \\
\hline Pathologic GS, mean \pm SD & $7.10 \pm 1.03^{\dagger}$ & $7.12 \pm 1.00^{\dagger}$ & $7.31 \pm 0.93$ & $0.018^{*}$ \\
\hline GS $\leq 6, n(\%)$ & $34(27.20)$ & $56(23.33)$ & $41(13.99)$ & \\
\hline $\mathrm{GS}=8, \mathrm{n}(\%)$ & $12(9.60)$ & $22(9.17)$ & $35(11.95)$ & \\
\hline $\mathrm{GS}=9,10, \mathrm{n}(\%)$ & $19(15.20)$ & $35(14.58)$ & $49(16.72)$ & \\
\hline Prostate volume (g), median (IQR) & $39.3(29.1-50.0)$ & $38.4(29.3-50.0)$ & $37.3(29.2-47.5)$ & 0.669 \\
\hline \multicolumn{5}{|l|}{ PSM, n (\%) } \\
\hline Overall & $38(33.04)$ & $91(40.63)$ & $110(39.15)$ & 0.383 \\
\hline pT2 & $17(44.74)$ & $34(37.36)$ & $36(37.73)$ & 0.893 \\
\hline pT3 & $21(55.26)$ & $56(61.58)$ & $74(67.27)$ & 0.062 \\
\hline pT4 & $0(0)$ & $1(1.10)$ & $0(0)$ & - \\
\hline
\end{tabular}

${ }^{\dagger}, \mathrm{P}>0.05$. ${ }^{*}$, comparison of groups by unpaired $t$-test. ${ }^{* * *}$, comparison of groups by Chi-square test. GS, Gleason score; PSM, positive surgical margin.

excellent choices for the treatment of organ-confined prostate cancer and locally advanced prostate cancer as they have superior overall perioperative outcomes and comparable pathological outcomes to those of ORPs. Moreover, the EBL and overall complications are significantly lower in RALRPs. Therefore, further prospective randomised studies with a higher caseloads and long-term oncological and functional follow-up are needed to designate RARP as the standard of care.

\section{Acknowledgments}

The authors thank Wijittra Matang, Yada Phengsalae and Kornkanok Somboonpun for continued support and encouragement.

This work was supported by Wijittra Matang, Yada
Phengsalae and Kornkanok Somboonpun.

\section{Footnote}

Conflicts of Interest: The authors have no conflicts of interest to declare.

Etbical Statement: The authors are accountable for all aspects of the work in ensuring that questions related to the accuracy or integrity of any part of the work are appropriately investigated and resolved. The principles of the Helsinki Declaration were followed during the study, and the confidentiality of the patients' data was guaranteed. The Committee for Research of the Faculty of Medicine, Ramathibodi Hospital, Mahidol University approved the study (date of approval: 01 October 2018, ID 07-61-70). 


\section{References}

1. National Cancer Institute Department of Medical Services Ministry of Public Health, Thailand. Hospital-based cancer registry 2015. Bangkok: National Cancer Institute; 2017.

2. Marcus HJ, Hughes-Hallett A, Payne CJ, et al. Trends in the diffusion of robotic surgery: A retrospective observational study. Int J Med Robot 2017;13. doi: 10.1002/rcs. 1870.

3. Nishimura K. Current status of robotic surgery in Japan. Korean J Urol 2015;56:170-8.

4. Akand M, Celik O, Avci E, et al. Open, laparoscopic and robot-assisted laparoscopic radical prostatectomy: comparative analysis of operative and pathologic outcomes for three techniques with a single surgeon's experience. Eur Rev Med Pharmacol Sci 2015;19:525-31.

5. Luciani LG, Mattevi D, Mantovani W, et al. Retropubic, Laparoscopic, and Robot-Assisted Radical Prostatectomy: A Comparative Analysis of the Surgical Outcomes in a Single Regional Center. Curr Urol 2017;11:36-41.

6. Parikh RR, Patel A, Kim S, et al. Comparative effectiveness of laparoscopic versus open prostatectomy for men with low-risk prostate cancer: a matched case-control study. Int J Surg Oncol (N Y) 2017;2:e13.

7. Seo HJ, Lee NR, Son SK, et al. Comparison of RobotAssisted Radical Prostatectomy and Open Radical Prostatectomy Outcomes: A Systematic Review and MetaAnalysis. Yonsei Med J 2016;57:1165-77.

8. Ubrig B, Boy A, Heiland M, et al. Outcome of Robotic Radical Prostatectomy in Men Over 74. J Endourol 2018;32:106-10.

9. Silberstein JL, Eastham JA. Significance and management of positive surgical margins at the time of radical prostatectomy. Indian J Urol 2014;30:423-8.

10. Walsh PC, Donker PJ. Impotence following radical prostatectomy: insight into etiology and prevention. J Urol 1982;128:492-7.

11. Yaxley JW, Coughlin GD, Chambers SK, et al. Robotassisted laparoscopic prostatectomy versus open radical retropubic prostatectomy: early outcomes from a randomised controlled phase 3 study. Lancet 2016;388:1057-66.

12. Wang L, Wang B, Ai Q, et al. Long-term cancer control outcomes of robot-assisted radical prostatectomy for prostate cancer treatment: a meta-analysis. Int Urol Nephrol 2017;49:995-1005.

13. De Carlo F, Celestino F, Verri C, et al. Retropubic, laparoscopic, and robot-assisted radical prostatectomy: surgical, oncological, and functional outcomes: a systematic review. Urol Int 2014;93:373-83.

14. Haglind E, Carlsson S, Stranne J, et al. Urinary Incontinence and Erectile Dysfunction After Robotic Versus Open Radical Prostatectomy: A Prospective, Controlled, Nonrandomised Trial. Eur Urol 2015;68:216-25.

15. Guillonneau B, Cathelineau X, Barret E, et al. Laparoscopic radical prostatectomy. Preliminary evaluation after 28 interventions. Presse Med 1998;27:1570-4.

16. Kongcharoensombat $W$, Tantirangsee $N$, Chaimuangraj $S$, et al. Comparison of extraperitoneal laparascopic radical prostatectomy and open retropubic radical prostatectomy at Ramathibodi Hospital, Thailand: A Retrospective review. J Med Assoc Thai 2012;95:1035.

17. Tobias-Machado M, Mitre AI, Rubinstein M, et al. Robotic-assisted radical prostatectomy learning curve for experienced laparoscopic surgeons: does it really exist? Int Braz J Urol 2016;42:83-9.

18. Thompson JE, Egger S, Böhm M, et al. Superior Quality of Life and Improved Surgical Margins Are Achievable with Robotic Radical Prostatectomy After a Long Learning Curve: A Prospective Single-surgeon Study of 1552 Consecutive Cases. Eur Urol 2014;65:521-31.

19. Ficarra V, Novara G, Artibani W, et al. Retropubic, laparoscopic, and robot-assisted radical prostatectomy: a systematic review and cumulative analysis of comparative studies. Eur Urol 2009;55:1037-63.

20. Hoznek A, Menard Y, Salomon L, et al. Update on laparoscopic and robotic radical prostatectomy. Curr Opin Urol 2005;15:173-80.

21. Mandel P, Linnemannstöns A, Chun F, et al. Incidence, Risk Factors, Management, and Complications of Rectal Injuries During Radical Prostatectomy. Eur Urol Focus 2018;4:554-7.

22. Wood DP, Schulte R, Dunn RL, et al. Short-Term Health Outcome Differences Between Robotic and Conventional Radical Prostatectomy. Urology 2007;70:945-9.

23. Wallerstedt A, Tyritzis SI, Thorsteinsdottir T, et al. Shortterm Results after Robot-assisted Laparoscopic Radical Prostatectomy Compared to Open Radical Prostatectomy. Eur Urol 2015;67:660-70.

24. Sachdeva A, Veeratterapillay R, Voysey A, et al. Positive surgical margins and biochemical recurrence following minimally-invasive radical prostatectomy - An analysis of outcomes from a UK tertiary referral centre. BMC Urol 2017;17:91.

25. De La Roca RL, Da Cunha IW, Bezerra SM, et al. Radical prostatectomy and positive surgical margins: 
relationship with prostate cancer outcome. Int Braz J Urol 2014;40:306-15.

26. Meeks JJ, Eastham JA. Radical prostatectomy: positive surgical margins matter. Urol Oncol 2013;31:974-9.

27. Pettenati C, Neuzillet Y, Radulescu C, et al. Positive

Cite this article as: Sirisopana K, Jenjitranant P, Sangkum P, Kijvikai K, Pacharatakul S, Leenanupun C, Kochakarn W, Kongchareonsombat W. Perioperative outcomes of roboticassisted laparoscopic radical prostatectomy, laparoscopic radical prostatectomy and open radical prostatectomy: 10 years of cases at Ramathibodi Hospital. Transl Androl Urol 2019;8(5):467475. doi: 10.21037/tau.2019.09.03 surgical margins after radical prostatectomy: What should we care about? World J Urol 2015;33:1973-8.

28. Yossepowitch O, Briganti A, Eastham JA, et al. Positive surgical margins after radical prostatectomy: a systematic review and contemporary update. Eur Urol 2014;65:303-13. 
Table S1 Time analysis of PSM

\begin{tabular}{|c|c|c|c|c|}
\hline PSM by years & ORP ( $n=128), n(\%)$ & $\operatorname{LRP}(n=241), n(\%)$ & RALRP (n=295), n (\%) & $P$ value \\
\hline Overall & 38 (33.04) & $91(40.63)$ & $110(39.15)$ & 0.383 \\
\hline 2008 & 6/38 (16.20) & 15/91 (16.48) & $0(0)$ & 0.873 \\
\hline pT2 & 4/6 (66.67) & 4/15 (26.67) & $0(0)$ & 0.070 \\
\hline pT3 & 2/6 (33.33) & $10 / 15(66.67)$ & $0(0)$ & 0.074 \\
\hline pT4 & $0(0)$ & $1 / 15(6.67)$ & $0(0)$ & - \\
\hline 2009 & $8 / 38(21.05)$ & 8/91 (8.79) & $0(0)$ & 0.746 \\
\hline pT2 & 4/8 (50.00) & 4/8 (50.00) & $0(0)$ & 0.746 \\
\hline pT3 & 4/8 (50.00) & 4/8 (50.00) & $0(0)$ & 1.000 \\
\hline pT4 & $0(0)$ & $0(0)$ & $0(0)$ & - \\
\hline 2010 & 1/38 (2.63) & 8/91 (8.79) & $0(0)$ & 0.326 \\
\hline pT2 & $1 / 1(100.00)$ & $1 / 8(12.50)$ & $0(0)$ & 0.383 \\
\hline pT3 & $0(0)$ & 7/8 (87.50) & $0(0)$ & $0.039^{\star \star \star}$ \\
\hline pT4 & $0(0)$ & $0(0)$ & $0(0)$ & - \\
\hline 2011 & 1/38 (2.63) & 5/91 (5.49) & $0(0)$ & 0.629 \\
\hline pT2 & $0(0)$ & $2 / 5(40.00)$ & $0(0)$ & 0.551 \\
\hline pT3 & $1 / 1(100.00)$ & $3 / 5(60.00)$ & $0(0)$ & 0.294 \\
\hline pT4 & $0(0)$ & $0(0)$ & $0(0)$ & - \\
\hline 2012 & $5 / 38(13.16)$ & 14/91 (15.38) & $0(0)$ & 0.294 \\
\hline pT2 & $2 / 5(40.00)$ & 7/14 (50.00) & $0(0)$ & 0.432 \\
\hline pT3 & $3 / 5(60.00)$ & 7/14 (50.00) & $0(0)$ & 0.387 \\
\hline pT4 & $0(0)$ & $0(0)$ & $0(0)$ & - \\
\hline 2013 & 4/38 (10.53) & 9/91 (9.89) & $12 / 110(10.91)$ & 0.520 \\
\hline pT2 & $2 / 4(50.00)$ & 6/9 (66.67) & 9/12 (75.00) & 0.404 \\
\hline pT3 & $2 / 4(50.00)$ & 3/9 (33.33) & $3 / 12(25.00)$ & 0.894 \\
\hline pT4 & $0(0)$ & $0(0)$ & $0(0)$ & - \\
\hline 2014 & 1/38 (2.63) & 12/91 (13.19) & $22 / 110(20.00)$ & 0.071 \\
\hline pT2 & $0(0)$ & 3/12 (25.00) & 12/22 (54.55) & $0.027^{\star \star \star}$ \\
\hline pT3 & 1/1 (100.00) & 9/12 (75.00) & $10 / 22(45.45)$ & 0.623 \\
\hline pT4 & $0(0)$ & $0(0)$ & $0(0)$ & - \\
\hline 2015 & 7/38 (18.42) & 7/91 (7.69) & $21 / 110$ (19.10) & 0.891 \\
\hline pT2 & $3 / 7(42.86)$ & $3 / 7$ (42.86) & 4/21 (19.05) & 0.262 \\
\hline pT3 & 4/7 (57.14) & $4 / 7(57.14)$ & 17/21 (80.95) & 0.276 \\
\hline pT4 & $0(0)$ & $0(0)$ & $0(0)$ & - \\
\hline 2016 & 4/38 (10.53) & 10/91 (10.99) & $33 / 110(30.00)$ & 0.949 \\
\hline pT2 & $1 / 4(25.00)$ & $4 / 10(40.00)$ & 4/33 (12.12) & 0.208 \\
\hline pT3 & $3 / 4(75.00)$ & 6/10 (60.00) & 29/33 (87.88) & 0.811 \\
\hline pT4 & $0(0)$ & $0(0)$ & $0(0)$ & - \\
\hline 2017 & 1/38 (2.63) & 3/91 (3.30) & $22 / 110(20.00)$ & 0.478 \\
\hline pT2 & $0(0)$ & $0(0)$ & 7/22 (31.82) & 0.397 \\
\hline pT3 & $1 / 1(100.00)$ & $3 / 3(100.00)$ & 15/22 (68.18) & 0.163 \\
\hline pT4 & $0(0)$ & $0(0)$ & $0(0)$ & - \\
\hline
\end{tabular}

${ }^{* * *}$, comparison of groups by the Chi-s(quare test. Data are presented as number (percent, \%). PSM, positive surgical margin; ORP, open radical prostatectomy; LRP, laparoscopic radical prostatectomy; RALRP, robotic-assisted laparoscopic radical prostatectomy. 


\begin{tabular}{|c|c|c|c|}
\hline Year & ORP $(\mathrm{N}=128), \mathrm{n}(\%)$ & $\operatorname{LRP}(\mathrm{N}=241), \mathrm{n}(\%)$ & RALRP (N=295), n (\%) \\
\hline \multicolumn{4}{|l|}{2008} \\
\hline $\mathrm{G} 1(\mathrm{GS} \leq 6)$ & $7(53.85)$ & $19(59.38)$ & $0(0)$ \\
\hline G2 $(G S=3+4)$ & $2(15.38)$ & $4(12.50)$ & $0(0)$ \\
\hline G3 $(\mathrm{GS}=4+3)$ & $2(15.38)$ & $5(15.63)$ & $0(0)$ \\
\hline $\mathrm{G} 4(\mathrm{GS}=8)$ & $1(7.69)$ & $4(12.50)$ & $0(0)$ \\
\hline G5 $(G S=9,10)$ & $1(7.69)$ & $0(0)$ & $0(0)$ \\
\hline \multicolumn{4}{|l|}{2009} \\
\hline $\mathrm{G} 1(\mathrm{GS} \leq 6)$ & $12(66.67)$ & $10(50.00)$ & $0(0)$ \\
\hline $\mathrm{G} 2(\mathrm{GS}=3+4)$ & $2(11.11)$ & $3(15.00)$ & $0(0)$ \\
\hline G3 (GS = 4+3) & $2(11.11)$ & $4(20.00)$ & $0(0)$ \\
\hline $\mathrm{G} 4(\mathrm{GS}=8)$ & $1(5.56)$ & $2(10.00)$ & $0(0)$ \\
\hline G5 $(G S=9,10)$ & $1(5.56)$ & $1(5.00)$ & $0(0)$ \\
\hline \multicolumn{4}{|l|}{2010} \\
\hline $\mathrm{G} 1(\mathrm{GS} \leq 6)$ & 2 (33.33) & $12(44.44)$ & $0(0)$ \\
\hline $\mathrm{G} 2(\mathrm{GS}=3+4)$ & $1(16.67)$ & $4(14.81)$ & $0(0)$ \\
\hline $\mathrm{G} 3(\mathrm{GS}=4+3)$ & $3(50.00)$ & $7(25.93)$ & $0(0)$ \\
\hline $\mathrm{G} 4(\mathrm{GS}=8)$ & $0(0)$ & $4(14.81)$ & $0(0)$ \\
\hline G5 $(G S=9,10)$ & $0(0)$ & $0(0)$ & $0(0)$ \\
\hline \multicolumn{4}{|l|}{2011} \\
\hline $\mathrm{G} 1(\mathrm{GS} \leq 6)$ & $3[60]$ & $9(52.94)$ & $0(0)$ \\
\hline $\mathrm{G} 2(\mathrm{GS}=3+4)$ & $1[20]$ & $2(11.76)$ & $0(0)$ \\
\hline G3 $(\mathrm{GS}=4+3)$ & $0(0)$ & $2(11.76)$ & $0(0)$ \\
\hline $\mathrm{G} 4(\mathrm{GS}=8)$ & $1[20]$ & $3(17.65)$ & $0(0)$ \\
\hline G5 $(\mathrm{GS}=9,10)$ & $0(0)$ & $1(5.88)$ & $0(0)$ \\
\hline \multicolumn{4}{|l|}{2012} \\
\hline $\mathrm{G} 1(\mathrm{GS} \leq 6)$ & $6(37.50)$ & $12(41.38)$ & $0(0)$ \\
\hline $\mathrm{G} 2(\mathrm{GS}=3+4)$ & $2(12.50)$ & $7(24.14)$ & $0(0)$ \\
\hline G3 (GS = 4+3) & $4(25.00)$ & 6 (20.69) & $0(0)$ \\
\hline $\mathrm{G} 4(\mathrm{GS}=8)$ & $1(6.25)$ & $2(6.90)$ & $0(0)$ \\
\hline G5 $(\mathrm{GS}=9,10)$ & $3(18.75)$ & $2(6.90)$ & $0(0)$ \\
\hline \multicolumn{4}{|l|}{2013} \\
\hline $\mathrm{G} 1(\mathrm{GS} \leq 6)$ & $6(37.50)$ & $9(39.13)$ & $14(46.67)$ \\
\hline $\mathrm{G} 2(\mathrm{GS}=3+4)$ & $5(31.25)$ & 4 (17.39) & 7 (23.33) \\
\hline $\mathrm{G} 3(\mathrm{GS}=4+3)$ & $1(6.25)$ & $5(21.74)$ & $6[20]$ \\
\hline $\mathrm{G} 4(\mathrm{GS}=8)$ & $0(0)$ & $2(8.70)$ & $3[10]$ \\
\hline $\mathrm{G} 5(\mathrm{GS}=9,10)$ & $4[25]$ & $3(13.04)$ & $0(0)$ \\
\hline \multicolumn{4}{|l|}{2014} \\
\hline $\mathrm{G} 1(\mathrm{GS} \leq 6)$ & $6(54.55)$ & $12(41.38)$ & $17[34]$ \\
\hline $\mathrm{G} 2(\mathrm{GS}=3+4)$ & $1(9.09)$ & 6 (20.69) & $13[26]$ \\
\hline G3 $(\mathrm{GS}=4+3)$ & $3(27.27)$ & $6(20.69)$ & 10 [20] \\
\hline $\mathrm{G} 4(\mathrm{GS}=8)$ & $1(9.09)$ & $1(12.50)$ & $6[12]$ \\
\hline G5 $(\mathrm{GS}=9,10)$ & $0(0)$ & $4(13.79)$ & $4[8]$ \\
\hline \multicolumn{4}{|l|}{2015} \\
\hline $\mathrm{G} 1(\mathrm{GS} \leq 6)$ & $4(22.22)$ & $5(23.81)$ & $16(26.67)$ \\
\hline $\mathrm{G} 2(\mathrm{GS}=3+4)$ & $5(27.78)$ & 7 (33.33) & $21(35.00)$ \\
\hline G3 (GS = 4+3) & $0(0)$ & $3(14.29)$ & $9(15.00)$ \\
\hline $\mathrm{G} 4(\mathrm{GS}=8)$ & $5(27.78)$ & $4(19.05)$ & $5(8.33)$ \\
\hline $\mathrm{G} 5(\mathrm{GS}=9,10)$ & $4(22.22)$ & $2(9.52)$ & $9(15.00)$ \\
\hline \multicolumn{4}{|l|}{2016} \\
\hline $\mathrm{G} 1(\mathrm{GS} \leq 6)$ & $3(27.27)$ & $13(50.00)$ & 24 (26.09) \\
\hline $\mathrm{G} 2(\mathrm{GS}=3+4)$ & $3(27.27)$ & 9 (34.62) & $20(21.74)$ \\
\hline G3 (GS = 4+3) & $1(9.09)$ & $3(11.54)$ & $17(18.48)$ \\
\hline $\mathrm{G} 4(\mathrm{GS}=8)$ & $2(18.18)$ & $0(0)$ & $18(19.57)$ \\
\hline $\mathrm{G} 5(\mathrm{GS}=9,10)$ & $2(18.18)$ & $1(3.85)$ & $13(14.13)$ \\
\hline \multicolumn{4}{|l|}{2017} \\
\hline $\mathrm{G} 1(\mathrm{GS} \leq 6)$ & $2(28.57)$ & $3(30.00)$ & 15 (26.32) \\
\hline $\mathrm{G} 2(\mathrm{GS}=3+4)$ & $2(28.57)$ & $5(50.00)$ & $14(24.56)$ \\
\hline G3 (GS $=4+3)$ & $1(14.29)$ & $0(0)$ & $12(21.05)$ \\
\hline $\mathrm{G} 4(\mathrm{GS}=8)$ & $2(28.57)$ & $1(10.00)$ & $11(19.30)$ \\
\hline G5 $(G S=9,10)$ & $0(0)$ & $1(10.00)$ & $5(8.77)$ \\
\hline
\end{tabular}

GS, Gleason score; G, grade group; ORP, open radical prostatectomy; LRP, laparoscopic radical prostatectomy; RALRP, robotic-assisted laparoscopic radical prostatectomy. 